\title{
Influence of testing mode on the fatigue behavior of $<111>$ austenitic grain at the nanometric length scale for TRIP steels
}

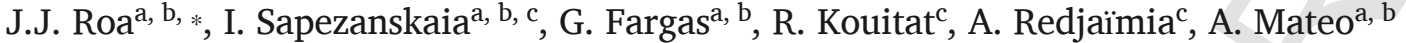 \\ a Department of Materials Science and Metallurgical Engineering, Universitat Politècnica de Catalunya, Campus Diagonal Besòs-EEBE, Barcelona 08019, Spain \\ ${ }^{\mathrm{b}}$ Centre for Research in Multiscale Engineering of Barcelona, Universitat Politècnica de Catalunya, Campus Diagonal Besòs-EEBE, Barcelona 08019, Spain \\ c Institut Jean Lamour, UMR 7198 CNRS, Université de Lorraine, Nancy Cedex 54000, France
}

\section{A R T I C L E I N F O}

\section{Keywords:}

Metastable austenitic stainless steels

Phase transformation

Cyclic indentation

Plastic deformation mechanisms

Transmission electron microscopy

Microstructural characterization techniques

\begin{abstract}
A B S T R A C T
Metastable austenitic stainless steels, and in particular the TRansformation Induced Plasticity steels, rely on a phase transformation from a ductile austenite to a slightly harder martensite. These materials under fatigue testing conditions at the macrometric length scale can induce a softening or hardening effect as a function of the underlying deformation feature activated. Thus, given the interaction of single grains in polycrystalline materials, the collective response to macroscopic fatigue testing is not trivial to interpret. Within this context, small scale tests are required to obtain a more in detail understanding of the fatigue properties at the local level of those materials. In this regard, cyclic nanoindentation tests represent a suitable technique to give insight on the local fatigue of metastable stainless steels for a certain crystallographic orientation. In this experimental work, the influence of the testing mode (loading and/or displacement control mode) on the fatigue behavior of $<111>$ austenitic grains as a function of their micromechanical properties as well as their deformation features was investigated in detail. It was found that the experiments done under loading control mode could be compared to conventional low cycle fatigue tests. In contrast when experiments were performed under displacement control mode they may be compared to high cycle fatigue tests. Furthermore, the microstructural observation by transmission electron microscopy allowed to observe the formation of shear bands. This phenomenon preceded the apparition of martensitic laths during the cyclic indentation process.
\end{abstract}

\section{Introduction}

Low-alloyed austenitic metastable stainless steels can undergo austenitic to martensitic phase transformation due to their low stacking fault energies (SFE). The implied TRansformation Induced Plasticity (TRIP) effect has extensive consequences for the mechanical properties, mainly under fatigue properties. Plastic deformation during the fatigue tests can lead to a deformation-induced transformation from the fcc austenite phase to the hcp $\varepsilon$-martensite or the bcc $\alpha^{\prime}$-martensite phase.

Given the high industrial interest of these steels for automotive applications [1], a good understanding of their fatigue properties, not only at the macrometric length scale but also at the microstructural local length scale (from an individual austenitic grain size), is crucial for appropriate design and usage. During the last years, several studies on the fatigue response of TRIP steels reported different mechanical and microstructural behaviors depending on the testing conditions [2-7]. It is well known that the formation of martensite during deformation is harmful in the low cycle fatigue (LCF) regime, i.e. under strain-control, while small martensitic content can be beneficial in the high cycle fatigue (HCF) regime, i.e. experiments under load-control mode. Thus, martensitic transformation under cyclic deformation can improve the high fatigue properties of metastable austenitic stainless steels $[8,9]$, since it contributes to crack closure or it retards crack propagation as reported by Chanani and Antolovich [3].

Within this context, in order to investigate the softening and/or hardening effect under conventional fatigue tests, it is important to differentiate between tests performed under stress or strain control mode as reported in Refs. [10-13].

In the present study, cyclic loading-unloading (P-h) tests were performed under different working modes (loading and/or displacement,

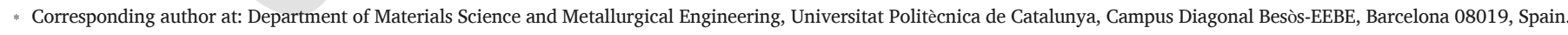
Email address: joan.josep.roa@upc.edu (J.J. Roa)
} 
which are equivalent to stress and strain control mode). The indentation test was supplemented by scanning and transmission electron microscope characterization in order to establish the connection between the conventional cyclic testing and get a better understanding of the existing relation between the mechanical and microstructural correlation.

\section{Experimental procedure}

\subsection{Material}

The material investigated in this work was a commercial annealed AISI 301LN stainless steel, equivalent to EN 1.4318, supplied by Outokumpu (Finland) as $1.5 \mathrm{~mm}$ thick sheets. Prior the mechanical and microstructural characterization, the as-received specimens were annealed at $1200{ }^{\circ} \mathrm{C}$ for $1 \mathrm{~h}$ in order to enlarge the initial grain size. The chemical composition is shown in Table 1. Subsequently, the TRIP steel specimens were polished with silicon carbide and then with a diamond suspension of 30, 6, 3 and $1 \mu \mathrm{m}$. Finally, a neutral suspension of $20 \mathrm{~nm}$ alumina particles was used in order to remove possible any work hardening produced in the surface layer during preparation. The average grain size for the austenitic phase was directly determined by the linear intercept method yielding a monomodal austenitic equiaxial grains distribution, whose sizes are $132.0 \pm 16 \mu \mathrm{m}$.

\subsection{Mechanical characterization}

The ultra-nanohardness tester (UNHT) from CSM instruments using a Berkovich tip indenter was employed to perform cyclic nanoindentation tests working under load and displacement control mode at a maximum applied load and displacement into surface of $6 \mathrm{mN}$ and $250 \mathrm{~nm}$, respectively. The cyclic loading-unloading tests was held constant and involved to 50 cycles, and the obtained data were analyzed using the Oliver and Pharr method [14,15]. The indenter shape has been carefully calibrated for true indentation depth as small as $20 \mathrm{~nm}$ by indenting fused silica samples of known Young's modulus (72 GPa). Furthermore, the loading and unloading rates of $10 \mathrm{mN} \mathrm{min}^{-1}$ as well as the holding period of $10 \mathrm{~s}$ between the cycles were held constant for all the tests, respectively.

\subsection{Microstructural characterization}

Crystal orientations in the region where the micromechanical properties were determined by means of Electron Backscattered Diffraction (EBSD). It was conducted in a Field Emission Scanning Electron Microscopy (FESEM) using a JEOL $7001 \mathrm{~F}$ unit equipped with an orientation imaging microscopy system. The diffraction response of grains oriented with a surface normal near the basal direction was sufficient for indexing with beam current in the order of $1 \mathrm{nA}$. EBSD measurements were performed with a constant scanning step $(100 \mathrm{~nm})$ at an acceleration voltage of $20 \mathrm{kV}$.

Transmission Electron Microscopy (TEM) was employed for detailed study of deformation mechanisms associated with plastic deformation induced during the cyclic indentation process. Hence, TEM lamellae were directly extracted by Focused Ion Beam (FIB) using a dual beam Workstation (Zeiss Neon 40). In doing so, prior to milling a thin platinum layer was deposited on residual imprints to be studied. $\mathrm{A} \mathrm{Ga}^{+}$ source was used, and current and acceleration voltage were progressively decreased to a final polishing stage of $10 \mathrm{pA}$. Deformation features within the FIB-milled lamellae were examined in a TEM equipment (Philips CM200 microscope) operating at $200 \mathrm{kV}$.

\section{Results and discussion}

Fig. 1 displays representative indentation loading-unloading curves (or P-h curves) for cyclic indentations performed on austenitic grains with the normal direction (ND) orientation close to $<111>$. The first $\mathrm{P}$-h indentation curve is characteristic for a ductile behavior, with a high irreversible plastic deformation (region confined between the loading and unloading curve) and a small elastic recovery upon unloading (region under the loading curve). Furthermore, during the following cycles, the deformation is fully elastic, where the loading and unloading curves per each cycle are overlapped. As it may be recognized in the displacement and loading control mode insets, labelled as (1) and (2), respectively, the presence of hysteresis loops is evident. That behavior may be related to the anelastic deformation. In the indentation tests performed under loading control mode the second and third cycles are open, a fact which may be related to the time-dependent plasticity exhibited which is known to occur in austenitic steels. This phenomenon, extensively investigated [16-23], is related to the accumulation strain generated during the cyclic indentation process, also known as ratcheting effect. The latter is not observed in tests performed under displacement control. The cyclic P-h curves for the experiments conducted under loading control mode, exhibit a softening effect. After the first cycle the load decreases as the number of cycles increases. In this sense, after the first unloading process, the austenitic grain slightly recovers the plastic deformation induced during the indentation process. However, subsequently the indenter deforms again in the same area, increasing the plastic deformation originated during the deformation process. Also, as it is evident in this figure, the softening behavior may be attributed to the nucleation and propagation of a high dislocation density generated under these testing conditions.

The evolution of hardness $(H)$ and the elastic modulus $(E)$ versus the cycle number are shown in Fig. 2a and $\mathbf{b}$ for tests undertaken under loading or displacement control modes, respectively. Initial values (1st cycle) for hardness and elastic modulus for both testing modes are in good agreement with those reported in the literature for austenitic metastable stainless steels [24], but vary from austenitic grain to grain depending on the crystallographic orientation as reported Roa et al. [25].

The hardness decreases when the number of cycle increases, until reaching a value of around 3.6 and $2.6 \mathrm{GPa}$ after 50 cycles for the tests performed under loading and displacement control mode, respectively. The hardness evolution for the tests performed under loading and displacement control mode is different as can be observed comparing Fig. 2a and b. In displacement tests the hardness (Fig. 2b) dramatically drops from the first to the second cycle and goes on falling down to the last cycle. In loading tests (Fig. 2a) a linear decreasing is observed. The hardness reduction or softening effect may be related to several factors, like the ratcheting behavior, as it was explained above. On the other hand, the austenitic grain is not thick enough to confine the plastic flow inside it, as well as the residual imprint was located at one edge of the austenitic grain.

Table 1

Chemical composition of the studied stainless steel AISI 301 LN (wt\%.).

\begin{tabular}{|c|c|c|c|c|c|c|c|c|}
\hline & $\mathrm{C}$ & $\mathrm{Cr}$ & $\mathrm{Ni}$ & Mn & $\mathrm{Si}$ & Mo & $\mathbf{N}$ & $\mathrm{Fe}$ \\
\hline AISI 301 LN & 0.02 & 17.48 & 7.03 & 1.23 & 0.45 & 0.12 & 0.12 & Bal. \\
\hline
\end{tabular}




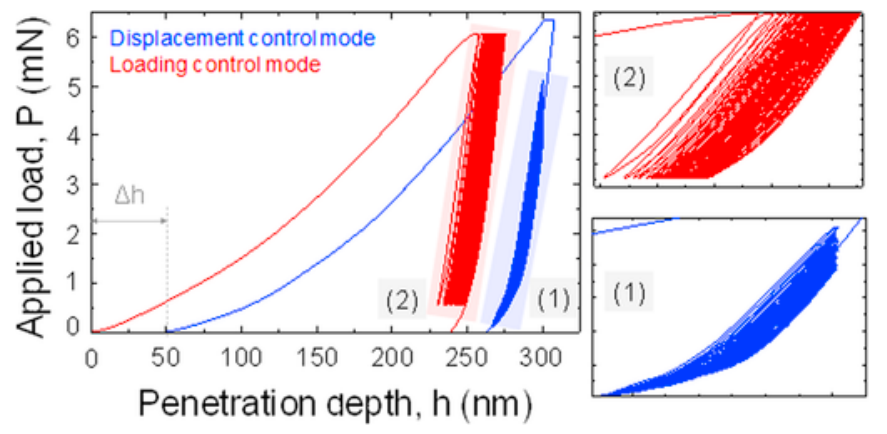

Fig. 1. Fifty cyclic indentation loading-unloading curves (or P-h curves) performed under displacement and loading control mode and labelled as (1) and (2), respectively. P-h curves for the experiments performed under displacement control mode have been shifted $50 \mathrm{~nm}$, to clearly discern the shape of the cycles. Insets present in the right hand side exhibit a magnification of the cyclic region. (a)

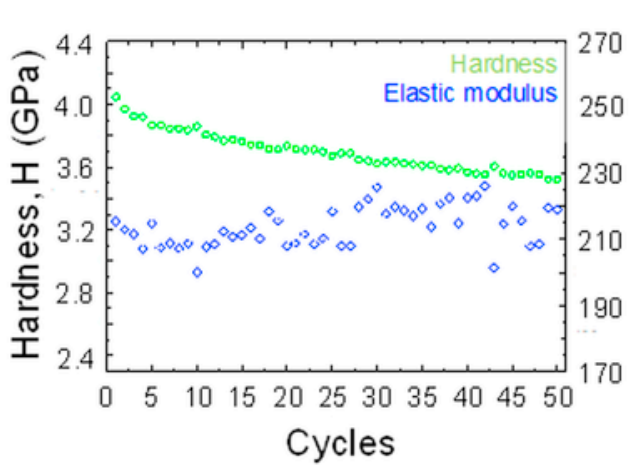

(b)

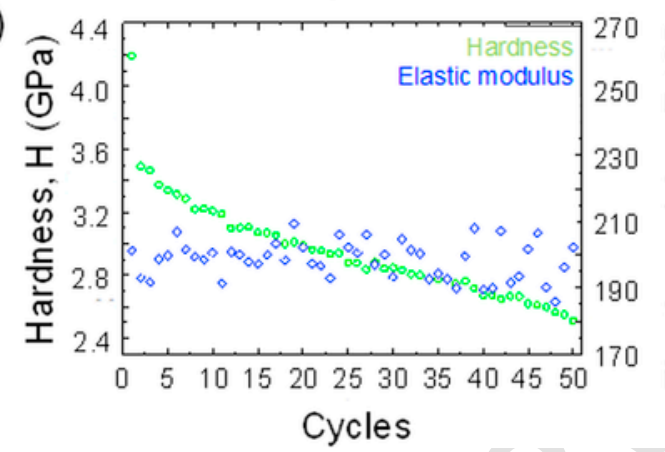

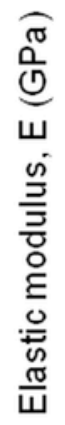

ชั $\frac{1}{10}$

ш (a)

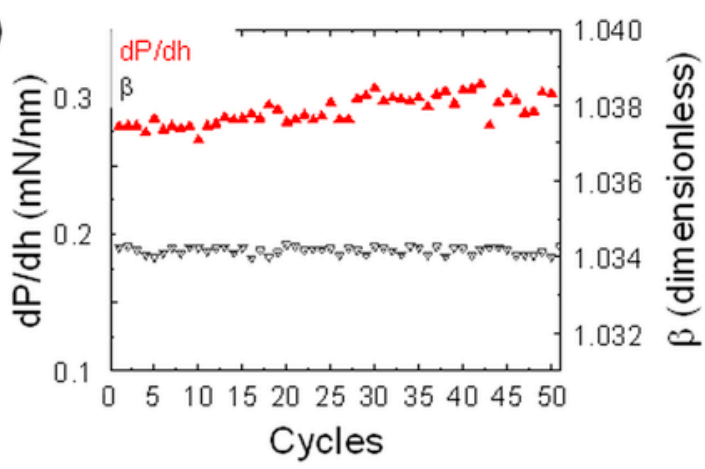

(b)

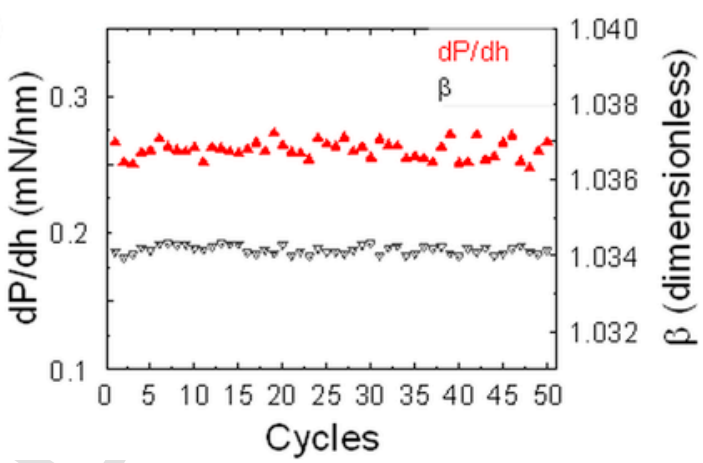

Fig. 3. Evolution of the contact stiffness $(\mathrm{dP} / \mathrm{dh})$ and $\beta$ against the cyclic evolution, determined under loading control mode (a) or under displacement control mode (b).

contact area only changes when the experiment is performed under loading control mode because the contact penetration depth $\left(h_{c}\right)$ slightly increases in each cycle. On the contrary, the $h_{c}$ value remains constant in experiments performed under displacement control mode.

Within this observation, the nanoindentation tests performed under displacement control mode can be compared to high cycle fatigue (HCF) tests, where the contribution of the elastic deformation is predominant than the plastic one in the total deformation. On the other hand, when the experiments were conducted under loading control mode they resemble to low cycle fatigue (LCF) testing, where plastic strain is more significant.

Aiming to evaluate the effect of the testing mode on the plastic deformation features activated on metastable austenitic stainless steels, a systematic study was conducted under displacement and loading control mode in a $<111>$ oriented austenitic grain. Fig. 4 a shows the corresponding local crystallographic mapping (or IPF map) determined by

Fig. 2. Hardness $(H)$ and elastic modulus $(E)$ evolution against the cycle, determined under loading control mode (a) or under displacement control mode (b).

The elastic modulus remained constant along all the cycles with values ranged between $210-220 \mathrm{GPa}$ and $185-210 \mathrm{GPa}$ for the tests performed under loading and displacement control mode, respectively. In this regard, both modes present a similar elastic modulus.

In order to validate the $H$ and $E$ values reported in Fig. 2 and make sure that the indenter shape did not change during the cyclic indentation process, the stiffness $(d P / d h)$ determined from the unloading curve and the geometrical factor $(\beta)$ is represented in Fig. 3 for each cycle. As it is evident, the $\beta$ factor for both testing modes remains constant at about 1.034, which is in fair agreement with that reported by Oliver and Pharr $[8,9]$. On the contrary, the $d P / d h$ value slightly increases for the specimen deformed under loading control mode, while it remains constant when the sample is tested under displacement control mode. It is well known that the $d P / d h$ parameter is related to the elastic properties (i.e. elastic modulus), which is an intrinsic property of each material and it may remain constant as reported in Fig. 2. This phenomenon observed in Fig. 3a, may be related to an evolution of the contact area between each indentation cycle. This confirms that the

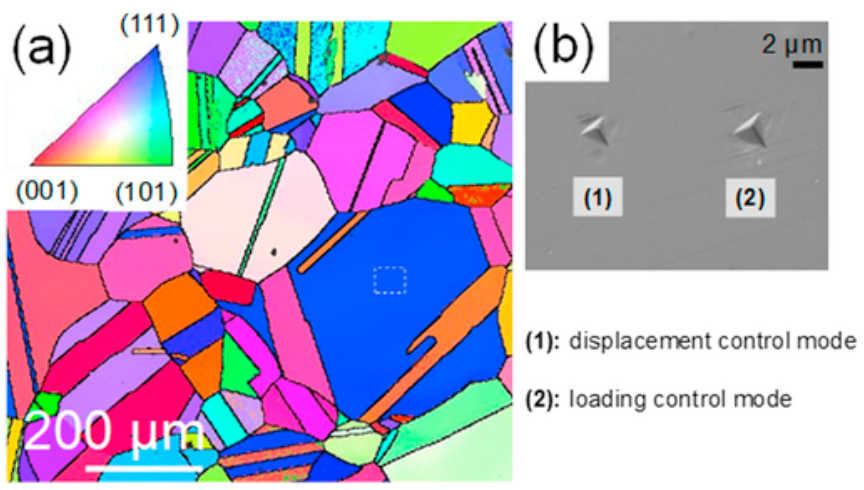

Fig. 4. (a) Local crystallographic orientation map (or Inverse Pole Figure map, IPF) determined by EBSD prior to the nanoindentation process. The dash white square exhibits the regions where the different indentation tests were performed. Step size was held constant and equals to $100 \mathrm{~nm}$, and (b) field emission scanning electron microscopy (FESEM) image of the residual cyclic imprints. The label (1) and (2) denote the indentation mode used to perform the test, displacement and loading control modes, respectively. 
means of EBSD, with the region indicated where the mechanical and structural characterization were performed. The region of interest is delimited by a white dash square on Fig. 4a. Furthermore, this IPF map highlights a high density of pre-existing twins generated during the annealing process. Two residual imprints performed on the $<111>$ austenitic grain are depicted in Fig. $4 \mathbf{b}$, labelled as (1) and (2) to denote the displacement and loading modes, respectively employed to perform the cyclic indentation tests. The plastic deformation field induced during the cyclic indentation process may be observed by the FESEM bright field contrast image around the imprint. Related deformation features aligned with $\{111\}$ traces are clearly observed, knowing that $\{111\}$ planes are the most common slip plane in fcc metallic alloys. As it is evident in this image, both residual imprints present that the same deformation features regardless of the tested method employed.

In order to get more detail about the plastic deformation induced under each testing condition, a thin foil of the center of the residual cyclic imprint was extracted by FIB and further examined by TEM. The analyzed thin foil corresponded to tests performed under displacement control mode at $250 \mathrm{~nm}$ of maximum displacement into surface (Fig. 5) or under load control mode at a maximum applied load of $6 \mathrm{mN}$, conducted between $10 \%$ of the peak working and the maximum value of displacement or load (Fig. 6).

A dense dislocation forest surrounding the deformed region could easily be distinguished in the bright field BF-TEM image (Fig. 5a). The electron diffraction pattern (Fig. 5c) revealed that no phase transformation occurred, while several plastic deformation features like forest dislocations, and shear bands are clearly evident. As example, the dark field DF-TEM image depicted in Fig. $5 \mathbf{b}$ shows a shear band underneath the residual imprint. In this regard, when a $<111>$ austenitic grain is deformed under displacement control mode, the TEM analysis highlights a heterogeneous microstructure with different prominent features as mentioned above, similar to the observed in preliminary works on deformed metastable stainless steel and reported in Refs. [26-28]. From the previous observation (Figs. 4 and 5), it becomes evident that the formation of shear bands must be preceded by the apparition of martensitic laths. This observation is in agreement with the results of Sabooni et al. [17], who reported that under cold rolling conditions a minimum amount of cumulative strain is required in order to induce martensitic laths at the macroscopic length scale. Das et al. [29] reached the same conclusion [17] when they investigated the martensitic content as a function of the number of fatigue cycles.

The deformation features activated when the cyclic tests were performed under loading control mode in a $<111>$ austenitic grain can be observed in the TEM images presented in Fig. 6 . Three shear bands of around $100 \mathrm{~nm}$ thick were activated under the obtuse side of the
Berkovich indenter, while a thinner one was induced in the acute indenter side (see white arrow in Fig. 6a). As it is evident in the BF-TEM image, the deformation features under the imprint are heterogeneous, showing a higher shear band density near one indenter side than in the other. This phenomenon may be related to the asymmetry of the Berkovich indenter, which produces a different stress state on each indenter side, as was already discussed by Miura et al. [30]. Furthermore, as can be seen in Fig. $6 \mathbf{c}$, all shear bands are parallel to each other and make an angle of about $70.5^{\circ}$ with respect to the surface plane. From the EBSD observation like the surface plane was (111) and the viewing direction [01ㅣ it can be concluded that shear bands lie on the oblique (111) slip plane. The SAED pattern (Fig. 6b) as well as the DF-TEM image (Fig. 6d) highlight that the thick shear bands induced during the cyclic indentation process have been partially transformed to $\alpha$ '-martensite. This observation, is in agreement with those tests performed by Kurdjumov et al. [31], indicating that the $\alpha$ '-martensitic phase evolved from the $\gamma$-phase, through the following relationship: $(111)_{\gamma} \|(011)_{\alpha^{\prime}}$ and $[01 \overline{1}]_{\gamma} \|[11 \overline{1}]_{\alpha^{\prime}}$. Talonen and Hänninen [32] found a close correlation between the shear bands and $\alpha^{\prime}$-martensite formation. Also, the relation between shear bands and $\alpha$ '-martensite, may be related to blocked-shape martensite structures form by nucleation and coalescence of $\alpha$ '-martensite embryos within a single shear band [33-36].

The non-transformed shear band presented in Fig. $7 \mathbf{a}$ and $\mathbf{b}$ presents a streaky appearance. This shape may be related to the many thin nanobands which compose this entire shear band (see Fig. 7b). On the other hand, in the upper part of the $\alpha^{\prime}$-martensitic shear band (Fig. 7c), a high forest dislocation is seen, which may be related to the distortion generated during the cyclic indentation process and the activation of this plastic feature. Furthermore, the DF-TEM (Fig. 7d), exhibits a highly deformed band, with a high density of dislocations inside of it. This observation is consistent with the existing knowledge about strain-induced martensitic phase transformation at the macroscopic length scale as reported in Refs. [37]. The observation done from Fig. 7c and $\mathbf{d}$ was previously done by Kim et al. [38], who found that $\alpha$ '-martensite formation under a nanoindent occurs in form of several blocks with different variants. These authors postulated that a sequential transformation takes places, with the resulting increase of misorientation and change of stress field when each new block is created. Also, Takaki et al. [39] observed some crystallographic rotations in the diffraction pattern, mainly related to crystallographic distortion generated during the plastic deformation. This behavior was previously observed at the macrometric length scale [40]. Therefore, not only the lattice rotations are expected to be larger as found in Ref. [41], resulting in a bigger $\alpha^{\prime}$-martensite region, but also a high density of shear bands and more dislocation will be emitted from the nanoindenter tip, contributing to slip bands formation.

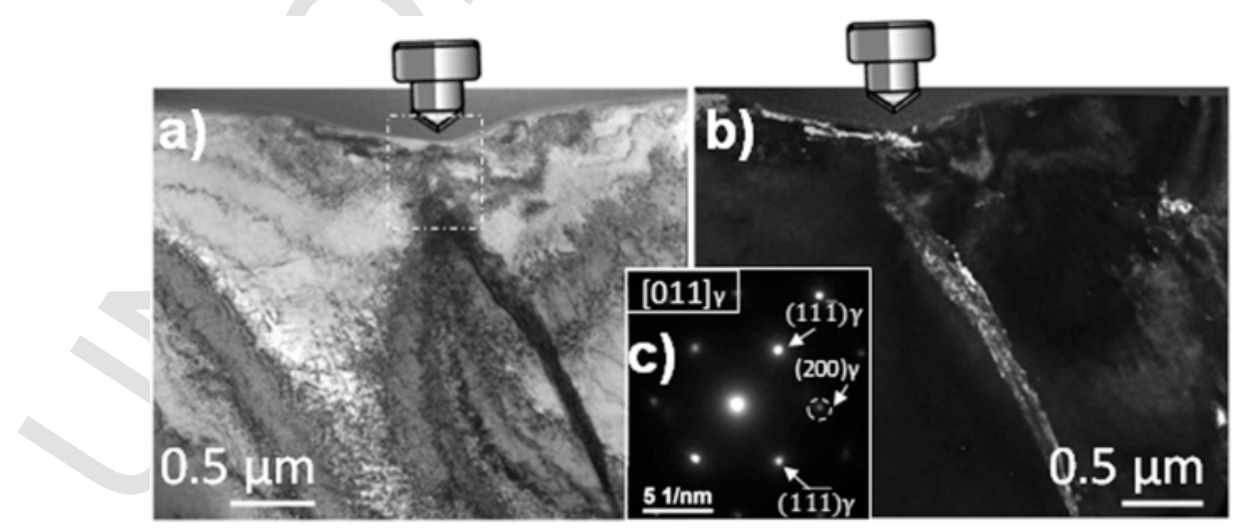

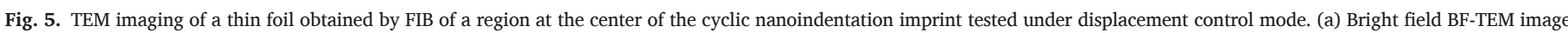

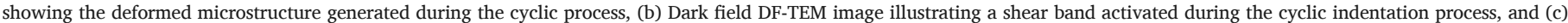
SAED pattern obtained from the region delimited by a white dash rectangle in a. 


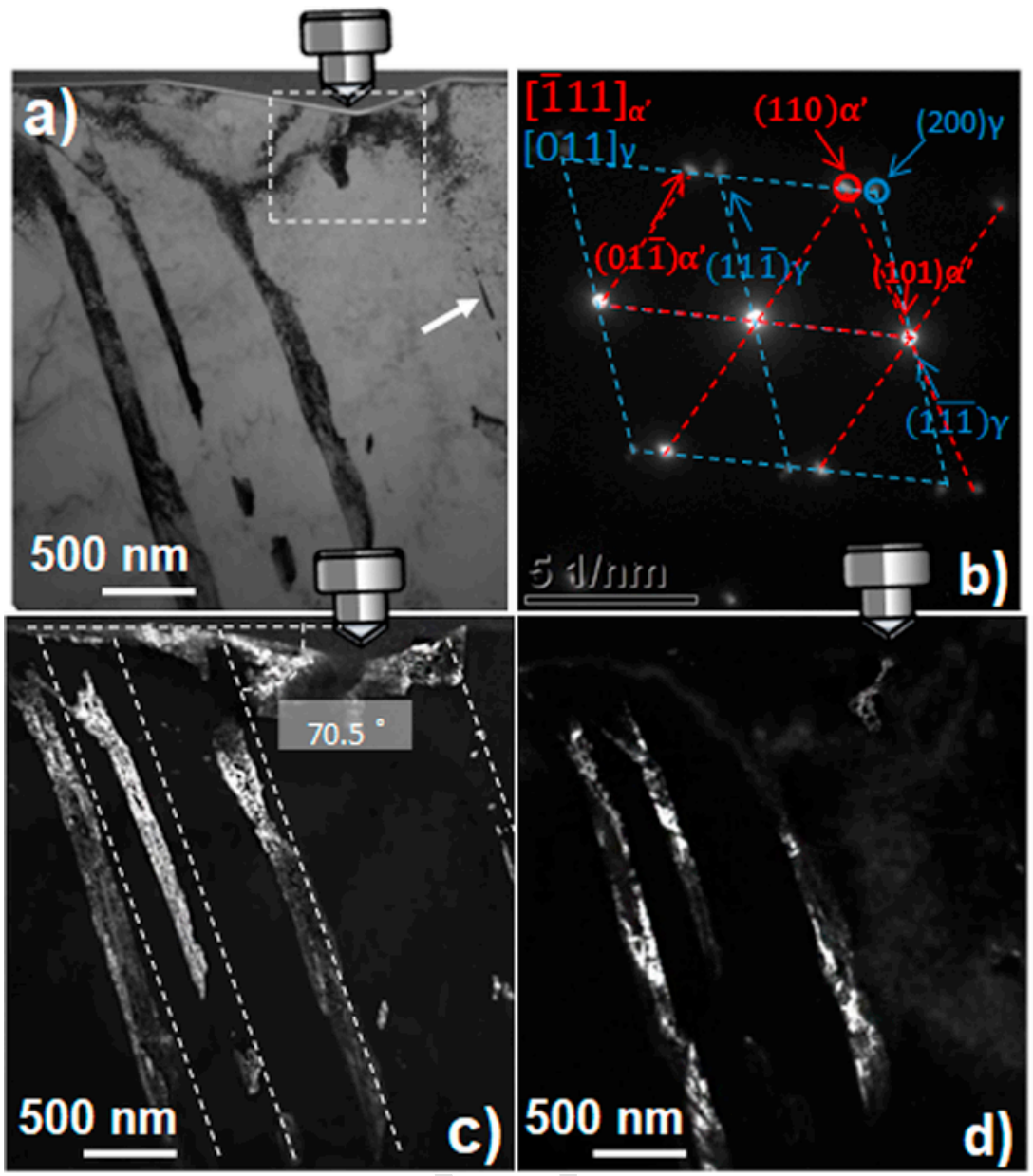

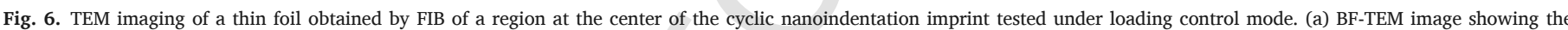

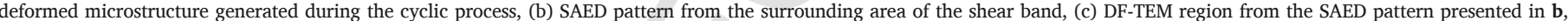
illustrating the different shear bands activated during the cyclic indentation process, and (d) DF-TEM image of $\alpha^{\prime}$-martensite lath forming inside of shear bands.
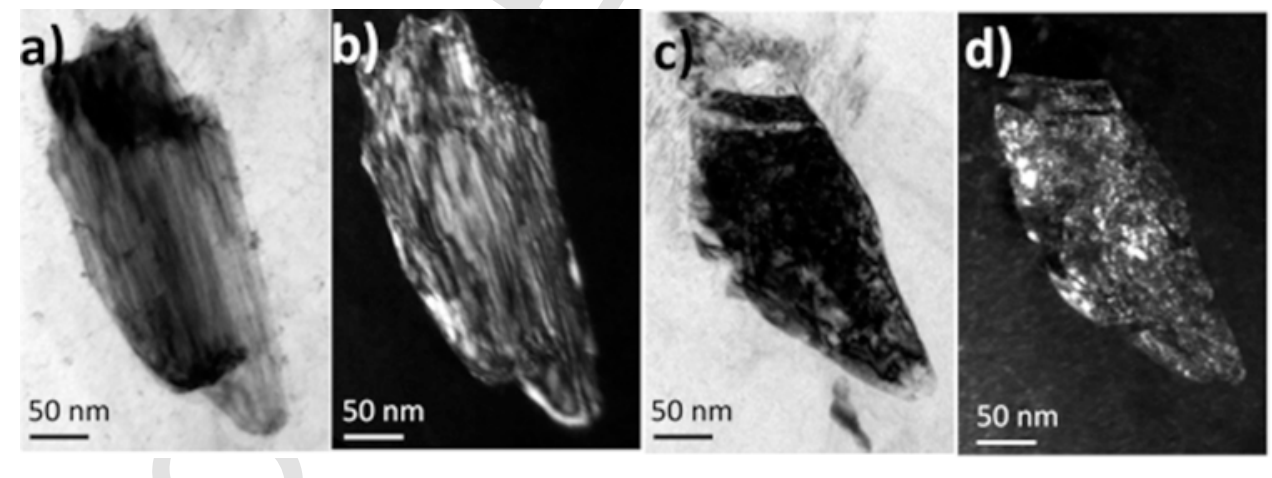

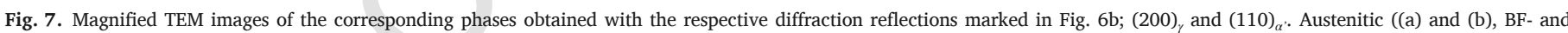
DF-TEM images, respectively) and $\alpha^{\prime}$-martensitic ((c) and (d), BF- and DF-TEM images, respectively) shear band sections.

Direct TEM observation under and near the residual imprint revealed tangled dislocations as well as a shear band parallel to the surface (Fig. 8 a). The shear band lies on the (111) plane as can be clearly appreciated in Fig. 8d, which shows a magnified region of the zone delimited by a square dash line in Fig. 8a. This figure reveals the presence of fine nanometric bundles, heterogeneously distributed between the martensitic phase and parallel to the growth direction of the latter. The corresponding SAED pattern (inset in Fig. 8d) reveals the presence of austenitic and $\varepsilon$-martensitic phase, whereby the arrangement in this bands leads to the appearance of streaks. It is believed that near the surface those nanometric bands serve as $\alpha^{\prime}$-martensitic nucleation sides.

Finally, from all the microstructural characterization performed by TEM analysis, it can be concluded that the character of the shear band determines the shape and morphology of the martensite laths, which is in agreement with Ref. [42]. 


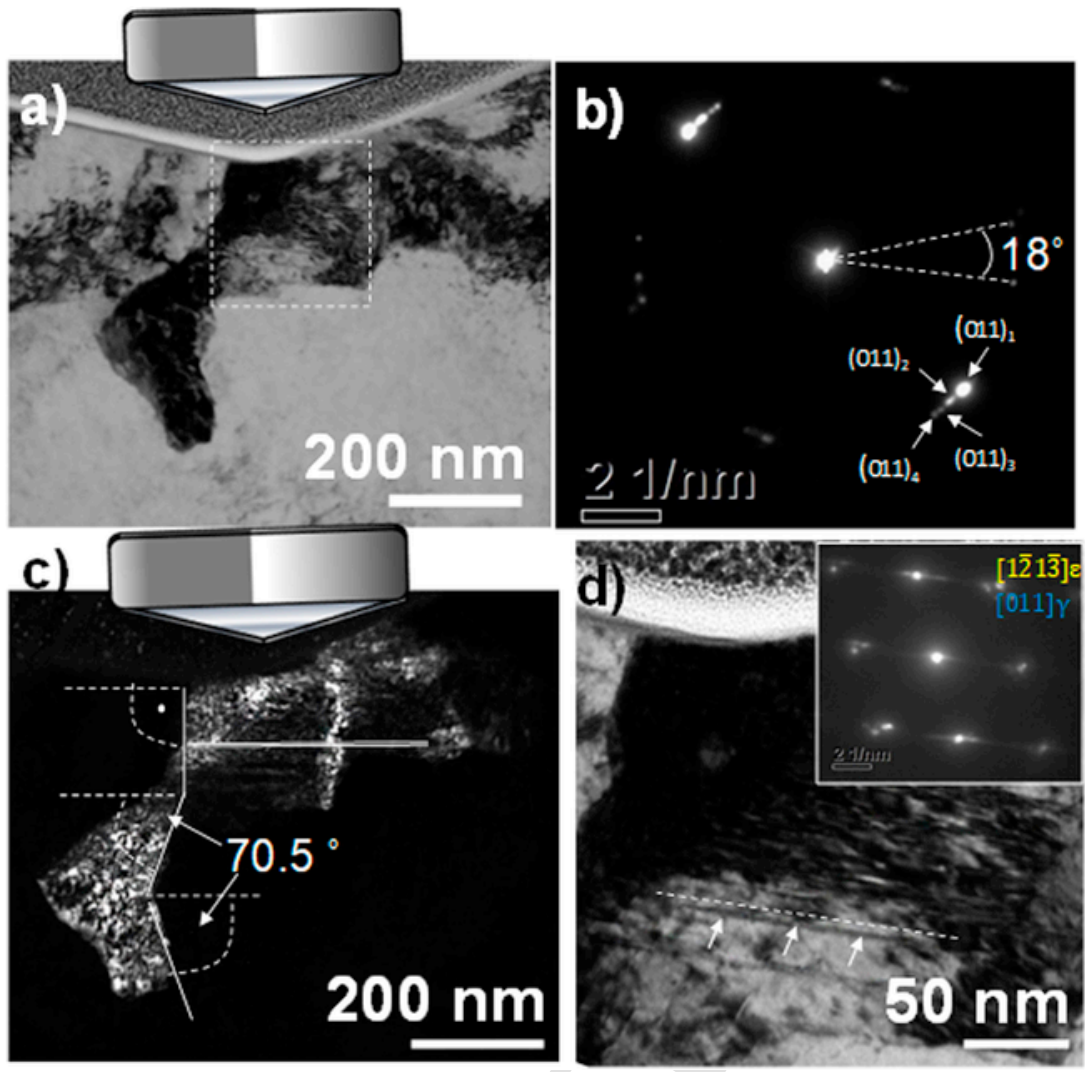

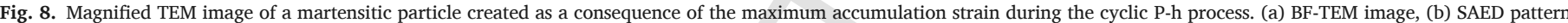

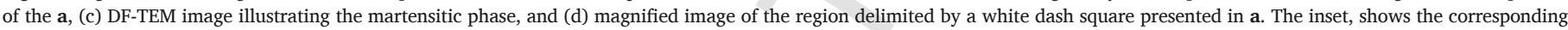
SAED area of the magnified region. The dashed line and arrows highlight a nanoscopic bundle created during the cyclic P-h process.

\section{Conclusions}

In this study cyclic nanoindentation tests were performed under different working modes (displacement and load control mode) on a $<111>$ austenitic grain in order to examine the micromechanical properties evolution as well as the plastic deformation features induced during the cyclic indentation process. The following conclusions may be drawn:

(i) The elastic modulus determined by using the loading or displacement control mode highlights that this parameter was strongly isotropic, while the hardness decreases when the number of cycles increases. This hardness reduction may be related with features of the activated plastic deformation.

(ii) Nanoindentation tests working under loading control mode can be compared to conventional low cycle fatigue tests whereas the experiments performed under displacement control mode may be compared to high cycle fatigue tests.

(iii) The TEM analysis indicated that the formation of shear bands must be preceded by the apparition of martensitic laths.

(iv) Cumulative deformation generated under loading control mode was significantly higher than that produced in displacement control mode, yielding an asymmetrically shear bans distribution under the cyclic indentation.

(v) Martensitic laths were not observed after fifty cyclic P-h curves when the experiment was performed under displacement control mode due to the cumulative strain generated was apparently too low compared with the strain generated when the experiment was undertaken under loading control mode.

\section{Acknowledgements}

Dr. I. Sapezanskaia would like to thanks DOCMASE program for its financial support. The authors also would like to thanks the technical support of T. Trifonov, I. López and S. Migot. Furthermore, the authors would like to acknowledge the financial support from the Spanish Government through the project MAT2015-70780-c4-3-P.

\section{References}

[1] J. Talonen, Effect of Strain-induced $\alpha$ '-Martensite Transformation on Mechanical Properties of Metastable Austenitic Stainless Steels, Helsinki University of Technology, 2007

[2] G.R. Chanani, S.D. Antolovich, W.W. Gerberich, Fatigue crack propagation in trip steels, Metall. Trans. 3 (1972) 2661-2672.

[3] G. Baudry, A. Pineau, Influence of strain-induced martensitic transformation on the low-cycle fatigue behavior of a stainless steel, Mater. Sc. Eng. 28 (1977) 229-242.

[4] C. Bathias, R.M. Pelloux, Fatigue crack propagation in martensitic and austenitic steels, Metall. Mater. Trans. B 4 (1973) 1265-1273.

[5] J. Stolarz, N. Baffie, T. Magnin, Fatigue short crack behaviour in metastable austenitic stainless steel with different grain sizes, Mater. Sci. Eng. A A319-A321 (2001) 521-526.

[6] M. Topic, R.B. Tait, C. Allen, The fatigue behaviour of metastable (AISI-304) austenitic stainless steel wires, Intern. J. Fatig 29 (2007) 656-665.

[7] A. Mateo, G. Fargas, A. Zapata, Martensitic transformation during fatigue testing of an AISI 301LN stainless steel, Mater. Sci. Eng. 31 (2012) 012010/1-012010/7.

[8] G.R. Chanani, S.D. Antolovich, W.W. Gerberich, Fatigue crack propagation in TRIP steels, Metall. Trans. 3 (1972) 2661-2672.

[9] Z. Mei, J.W. Morris, Influence of deformation-induced martensite on fatigue crack propagation in 304-type steels, Metall. Trans. A 21 (1990) 3137-3152.

[10] J.C. Figueroa, S.P. Bhat, R. De la Veaux, S. Murzenski, C. Laird, The cyclic stress-strain response of copper at low strains-I. Constant amplitude testing, Acta Metall. 29 (1981) 1667-1678.

[11] L. Llanes, C. Laird, Effect of loading mode on the cyclic response and the associated substructure of polycrystalline copper in the high-cycle regime, Fatigue Fract. Eng. Mater. Struct. 16 (1993) 165-179. 
[12] L. Llanes, C. Laird, Substructure evolution of copper polycrystals under different testing conditions: conventional strain control and ramp loading, Mater. Sci. Eng. A 161 (1993) 1-12.

[13] S. Taheri, A. Hauet, L. Taleb, C. Kpodekon, Micro-macro investigations about the fatigue behavior of pre-hardened 304L steel, Int. J. Plast. 27 (2011) 1981-2004.

[14] W.C. Oliver, G.M. Pharr, An improved technique for determining hardness and elastic modulus using load and displacement sensing indentation experiments, J. Mater. Res. 7 (1992) 1564-1583.

[15] W.C. Oliver, G.M. Pharr, Measurement of hardness and elastic modulus by instrumented indentation: advances in understanding and refinements to methodology, J. Mater. Res. 19 (2004) 3-20.

[16] F. Yoshida, Uniaxial and biaxial creep-ratcheting behavior of SUS304 stainless steel at room temperature, Int. J. Press. Vessel. Pip. 44 (1990) 207-223.

[17] N. Ohno, M. Abdel-Karim, Uniaxial ratchetting of 316FR Steel at room temperature-Part II: constitutive modeling and simulation, J. Eng. Mater. Technol. 122 (2000) 35-41.

[18] D. Kujawski, V. Kallianpur, E. Krempl, An experimental study of uniaxial creep, cyclic creep and relaxation of AISI type 304 stainless steel at room temperature, $\mathrm{J}$. Mech. Phys. Solids 28 (1980) 129-148.

[19] Y. Mima, N. Ohno, Uniaxial ratchetting of 316 FR Steel at room temperature - Part I: Experiments J. Eng. Mater. Technol 122 (2000) 29-34.

[20] E. Krempl, M.B. Ruggles, The interaction of cyclic hardening and ratchetting for AISI type 304 stainless steel at room temperature - II. Modeling with the viscoplasticity theory based on overstress, J. Mech. Phys. Solids 38 (1990) 587-597.

[21] M.B. Ruggles, E. Krempl, The influence of test temperature on the ratchetting behavior of type 304 stainless steel, J. Eng. Mater. Technol. 111 (1989) 378-383.

[22] J.R. Ellis, D.N. Robinson, C.E. Pugh, Time dependence in biaxial yield of type 316 Stainless Steel at room temperature, J. Eng. Mater. Technol. 105 (1983) 250-256.

[23] R.D.K. Mirsa, P. Venkatsurya, K.M. Wu, L.P. Karjalainen, Ultrahigh strength martensite-austenite dual-phase steels with ultrafine structure: the response to indentation experiments, Mater. Sci. Eng. A 560 (2013) 693-699.

[24] A. Weidner, U.D. Hangen, H. Biermann, Nanoindentation measurements on deformation induced $\alpha$ '-martensite in a metastable austenitic high-alloy CrMnNi steel, Philos. Mag. Lett. 94 (2014) 522-530.

[25] J.J. Roa, G. Fargas, A. Mateo, E. Jiménez-Piqué, Dependence of nanoindentation hardness with crystallographic orientation of austenite grains in metastable stainless steels, Mat. Sci. Eng. A 645 (2015) 188-195.

[26] A. Mateo, G. Fargas, A. Zapata, Martensitic transformation during fatigue testing of an AISI 301 LN stainless steel, IOP Conf. Ser. Mater. Sci. Eng. 31 (2012) 012010/ 1-012010/7..

[27] P. Hausild, J. Nohava, P. Pilvin, Characterisation of strain-induced martensite in a metastable austenitic stainless steel by nanoindentation, Strain 47 (2011) 29-133.
[28] I. Sapezanskaia, J.J. Roa, G. Fargas, M. Turon-Viñas, T. Trifonov, R. Kouitat Njiwa, A. Redjaïmia, A. Mateo, Deformation mechanisms induced by nanoindentation tests on a metastable austenitic stainless steel: a FIB/SIM investigation, Mater. Charact. 131 (2017) 253-260.

[29] A. Das, Magnetic properties of cyclically deformed austenite, J. Magn. Magn. Mater. 361 (2014) 232-242.

[30] T. Miura, K. Fujii, K. Fukuya, K. Takashima, Influence of crystal orientation on hardness and nanoindentation deformation in ion-irradiated stainless steels, J. Nucl. Mater. 417 (2011) 984-987.

[31] G. Kurdjumov, G.Z. Sachs, About the mechanisms of steel hardening, Physik 64 (1930) 325-343.

[32] J. Talonen, H. Hänninen, Formation of shear bands and strain-induced martensite during plastic deformation of metastable austenitic stainless Steel, Acta Mater. 55 (2007) 6108-6118.

[33] K. Staudhammer, L. Murr, S. Hecker, Nucleation and evolution of strain-induced martensitic (bcc) embryos and substructure in stainless steel: a transmission electron microscope study, Acta Metall. 31 (1983) 267-274.

[34] S. Sabooni, F. Karimzadeh, M.H. Enayati, A.H.W. Ngan, The role of martensitic transformation on bimodal grain structure in ultrafine grained AISI 304L stainless steel, Mater. Sci. Eng. A 636 (2015) 221-230.

[35] J.B. Seol, J.E. Jung, Y.W. Jang, C.G. Park, Influence of carbon content on the microstructure, martensitic transformation and mechanical properties in austenite/martensite dual-phase Fe-Mn-C steels, Acta Mater. 6 (2013) 558-578.

[36] S. Martin, S. Wolf, U. Martin, L. Krüger, A. Jahn, Investigations on martensite formation in CrMnNi-TRIP steels, ESOMAT 2009-8th Eur. Symp. Martensitic Transform. 05022 1-7.

[37] H.K.D.H. Bhadeshia, R.W.K. Honeycombe, Steels: Microstructure and Properties, Elsevier, Butterworth-Heinemann, 2006.

[38] Y. Kim, T.H. Ahn, D.W. Suh, H.N. Han, Variant selection during mechanically induced martensitic transformation of metastable austenite by nanoindentation, Scr. Mater. 104 (2015) 13-16.

[39] S. Takaki, K. Tomimura, S. Ueda, Effect of pre-cold-working on diffusional reversion induced martensitic in metastable austenitic stainless Steel, ISIJ Int. 34 (1994) 522-527.

[40] F. Yang, L. Peng, K. Okazaki, Cyclic indentation in aluminum, J. Mater. Sci. 42 (2007) 4513-4520.

[41] D. Kiener, K. Durst, M. Rester, A.M. Minor, Revealing deformation mechanisms with nanoindentation, Nanomech. Charact. 61 (2009) 14-23.

[42] E. Cakmak, H. Choo, J. -Y. Kang, Y. Ren, Relationships between the phase transformation kinetics, texture evolution, and microstructure development in a $304 \mathrm{~L}$ stainless steel under biaxial loading conditions: synchrotron X-ray and electron backscatter diffraction studies, Metall. Mater. Trans. A 46 (2015) 1860-1877. 